\title{
Mamá, quiero ser artista. \\ La situación actual de la mujer en el panorama artístico
}

\author{
Mum, I want to be an artist. \\ The current situation of women in the artistic scene
}

\author{
M José Ruiz FernÁNDEZ \\ Facultat de Geografia e Història. Universitat de València \\ majorf86@gmail.com
}

Recibido: 13 de octubre de 2010

Aprobado: 23 de febrero de 2011

\begin{abstract}
Resumen
La lucha reivindicativa de la mujer por hacerse un hueco en el panorama artístico se acentúa en los años setenta con grandes artistas que defienden sus derechos en Estados Unidos y Europa a través de nuevos medios como la fotografía o la performance. Éstas van abriendo hueco a sus generaciones posteriores.

La herencia que ellas han dejado permite a la mujer trabajar sin plantearse cuestiones de género como sí se hacía en el pasado, aunque este hecho no significa que esté todo solucionado y que haya que bajar la guardia. La artista Natalia Lozano, artista emergente multidisciplinar, sirve como ejemplo para conocer qué situación se encuentra una mujer joven hoy en día y permite sacar una lectura postfeminista. Además la catedrática Rosa María Rodríguez Magda responde a algunas cuestiones que ayudan a despejar ciertas dudas que surgen al conocer el panorama actual.
\end{abstract}

Palabras Clave: Feminismo, Postfeminismo, Natalia Lozano, Estudios de Género.

Ruiz Fernández, Ma J. 2011: Mamá, quiero ser artista. La situación actual de la mujer en el panorama artístico. Arte, Individuo y Sociedad, 23 (2), 23-34

\begin{abstract}
Woman vindictive fight to take place in the artistic scene accents in the seventies, with big artists that defend their rights in The United States and Europe with new media like photography or performances. These new media opened the road to their later generations.

The inheritance they have left allows woman to work without thinking about gender matters like they did in the past, but this fact doesn't mean that all is solved and they can lower their guard. Natalia Lozano, emergent multidisciplinary artist, is a good example to know in what situation a young woman is nowadays, and also allow us to extract a postfeminist reading. Moreover, the professor Rosa Maria Rodríguez Magda answers some questions that help us to solve certain points that come when you know the current scene.
\end{abstract}

Key Words: Feminism, Postfeminism, Natalia Lozano, Gender Studies.

Ruiz Fernández, M J J. 2011: Mum, I want to be an artist. The current situation of women in the artistic scene . Arte Individuo y Sociedad, 23 (2), 23-34 
Sumario: 1. Introducción, 2. Años 70 y el despertar de la conciencia femenina en el arte, 3. Natalia Lozano, 4. Lectura Postfeminista, 5. Conclusiones. Referencias

\section{Introducción}

Natalia Lozano no es una artista cuya producción tenga una relación directa con el feminismo o el postfeminismo, lo interesante es ver cómo toda la lucha por los derechos de la mujer a lo largo de la historia ha llegado a nuestra sociedad y se ve reflejado en artistas como Natalia que no se plantea su condición de mujer en el trabajo. Su poca experiencia supone una dificultad a la hora de integrarse en el mundo del arte, pero además debemos preguntarnos si el hecho de ser mujer afecta también a esta integración.

Tras analizar su carrera y sus obras, se recogen sus impresiones y sus valoraciones acerca del tema y finalmente con todo ello, se podrán sacar unas conclusiones postfeministas. Se pretende con este artículo dar una visión positiva de toda la labor que han hecho las mujeres a lo largo de la historia y hacer ver cómo, hoy en día, a pesar de que aún queda mucho camino por recorrer, recogemos los frutos.

Natalia Lozano, una artista emergente que empieza a integrarse en este difícil mundo del arte, nos permite ver si se han roto todos los tabú acerca del machismo en el arte.

No será hasta la década de los 70 del siglo XX cuando la mujer comienza a alzar la voz y a afirmar la identidad femenina en la cultura y la sociedad. De hecho, hubo una vigorosa presencia femenina tanto de artistas como de críticas, comisarias de exposiciones, etc. que supieron proclamarse como artistas-mujeres, y es que la identidad ha jugado un papel fundamental en la formación de los movimientos contemporáneos para la lucha feminista entre otras. ${ }^{1}$

Hoy en día, en pleno siglo XXI, hemos superado muchas trabas pero se debe tener en cuenta que existe dificultad en la integración cuando además una mujer está empezando, cuando se trata de una artista que intenta abrirse un hueco en este difícil mundo como es el caso de Natalia Lozano.

Pero esta artista, no pertenece al conjunto de mujeres revolucionarias y feministas que utilizaron su obra de arte como instrumento de reivindicación, además de manifestaciones, marchas, publicaciones, reuniones, etc. sino que, gracias al esfuerzo que éstas realizaron y realizan en este momento, las artistas pueden permitirse trabajar sin diferenciar entre géneros. Poco a poco, se está abriendo un camino de igualdad e integración en la sociedad en el que la mujer es partícipe y su voz se escucha.

Natalia Lozano se enmarca en un contexto en el que tras el alzamiento de la voz femenina (no sólo mujer de la mujer blanca y anglosajona tras el llamado postfeminismo) se llega al punto de teorizar un feminismo más igualitario y no tan radical como en sus inicios, aunque éste no desaparece.

En la actualidad las artistas trabajan, crean y participan en la actividad artística sin plantearse a qué género pertenecen, sin pensar que su trabajo va a ser juzgado según el género de quien lo ha realizado, la condición sexual o raza.

Vamos a conocer la obra de una joven artista que no se plantea cuestiones de género, sin querer hacer un arte reivindicativo, sin pararse a pensar si su obra será marginada o no por el hecho de ser mujer. ¿Hemos llegado a la igualdad? 


\section{Años 70 y el despertar de la conciencia femenina en el arte}

En la actualidad, una persona cuando acude a una exposición, pocas veces se pregunta si la obra que está viendo la ha realizado una mujer o un hombre. Pero, ¿la mujer juega el mismo papel que el hombre en el arte actual? Desde hace ya cuarenta años la mujer comienza a afirmar su identidad en la sociedad y en la cultura, se dará vida a una realidad inédita, de igualdad entre sexos y una nueva percepción del cuerpo y de su nuevo papel.

Estas primeras mujeres reivindicativas han dejado un legado que pretende poder ser mujeres al mismo tiempo que artistas. El arte femenino relegado hasta el momento a un papel de subordinación se alza con una fuerza y una conciencia desconocidas hasta el momento. ${ }^{2}$

Todo esto comienza a darse en los EE. UU y Europa donde artistas como Judy Chicago, considerada una de las pioneras en el movimiento feminista se cuestionaba el sistema patriarcal y reflexionaba sobre el cuerpo, la identidad, etc. También las Guerrilla girls, grupo de artistas feministas que nace en Nueva York en 1985 tras la exposición An International Survey of Painting and Sculpture en el Museum of Modern Art de New York donde de una lista de 169 artistas solo 13 eran mujeres y todos eran blancos sin excepciones, americanos o europeos; el grupo se dedicó a promocionar la presencia de la mujer artista en el arte, denunciando el desequilibrio de género y racial, llevan siempre una máscara de gorila y una estética muy femenina para dar un mensaje reivindicativo. También Cindy Sherman, Barbara Kruger o europeas como las alemanas Rebecca Horm y Rosemarie Trockel o la italiana Carla Accardi supieron manifestar su interés por la situación de la mujer.

Este feminismo que surge en las últimas décadas del siglo XX, que sobre todo intentó crear oposición en los mass media ${ }^{3}$ para romper con los tópicos sociales, da paso a un feminismo con nuevos planteamientos como la homosexualidad, el sexo, la pornografía, la raza, etc. Es el llamado postfeminismo y con él el feminismo empieza a preocuparse de las diferencias, en plural, y no sólo de la diferencia sexual ${ }^{4}$. Surge la teoría Queer con la que se pretenden una integración de la homosexualidad en a sociedad. También la pornografía, que al igual que la teoría queer, ha sido un tema muy recurrido en las reivindicaciones postfeministas. El postcolonialismo también ocupa un lugar importante en el postfeminismo, pone sobre la mesa un debate racial. Según Olga Barrios 5 , es a partir de los años 70 cuando el mundo empieza a abrir los ojos ante esta realidad, ante la existencia de sociedades multiculturales y la diversidad artística que podían aportar. Por último, hay que resaltar la creación del llamado Cyberfeminismo, una nueva opción frente al feminismo clásico que nos acerca a las nuevas tecnologías hasta el momento dominadas por el hombre. El ciberespacio es un nuevo territorio que la mujer debe aprovechar para continuar su lucha.

Pero, ¿cómo han calado en la sociedad todas estas reivindicaciones de carácter feminista? ¿Se les ha dado la espalda a estas teorías o la mujer cada vez tiene un papel mayor y más influyente en el mundo del arte? Hoy en día sí parece que el trabajo de la mujer es reconocido sobre todo si la artista ya ha fallecido por lo que su obra se revaloriza como por ejemplo Frida Kahlo o si tiene una carrera ya consolidada 
como puede ser Cindy Sherman que se encuentra entre las artistas más valoradas del mercado del arte.

¿Pero qué sucede cuando nos encontramos ante una artista joven, que está empezando y quiere integrarse como artista como es el caso de Natalia Lozano? ¿Ha calado hasta tal punto la lucha feminista, o aún la mujer encuentra dificultades a la hora de despegar su carrera? Para responder estas preguntas no tenemos más que detenernos en la última Bienal de Venecia que constituye un claro ejemplo de los que ocurre actualmente en arte.

La Bienal De Venecia, una de las instituciones culturales más prestigiosas del mundo, este año titulada Fare Mondi, ha otorgado el premio como mejor artista joven a la sueca Nathalie Djurberg, nacida en 1978 en Lysekil. Djurberg muestra en Venecia una instalación que recrea un jardín del infierno, con colores, formas y tamaños que hacen al espectador echarse atrás, todo acompañado con música de Hans Gerg. Las pantallas muestran las relaciones de poder y sexo entre marionetas hechas de plastilina. Además también se reconoce con un premio toda la carrera de la artista japonesa Yoko Ono, artista ya consolidada y que se ha caracterizado, entre otras cosas, por la reivindicación feminista sobre todo a través de la performance. También destaca la joven inglesa Miranda July, cuyo trabajo, fue interpretado muy positivamente por el público y su nombre se ha asentando con fuerza en el panorama artístico internacional.

Con este dato se pretende ver el lado positivo de la lucha feminista, una joven artista ha sido reconocida con el León de Plata en una de las muestras más importantes.

La mujer está tomando cada vez más protagonismo en el arte, pues este hecho era impensable un siglo atrás. La lucha feminista y postfeminista está calando poco a poco en la sociedad. En la muestra han participado 95 artistas, 39 eran mujeres, un dato destacado teniendo en cuenta, por ejemplo, la exposición en 1985 An International Survey of Painting and Sculpture en el Museum of Modern Art de New York en la que una lista de 169 artistas sólo 13 eran mujeres.

Pero, por otro lado, no pretendo afirmar que ya está todo hecho, sin ir más lejos la publicidad aún hoy nos muestra una imagen estereotipada de la mujer a pesar de que desde los años 70 se intenta romper con esto. La moda ha sido un arma utilizada por las mujeres, además de las manifestaciones artísticas como la performance, para manifestar su lucha vistiendo como los hombres, sin dejar lugar a diferencias pero la imagen publicitaria es el elemento más cercano a la gente que manifiesta aún un machismo latente.

Existen aun hoy exposiciones colectivas en las que el número de mujeres es escaso, un ejemplo, Valencia, exposición que tuvo lugar en el Centre del Carme, La huella fotográfica en la nueva pintura realista. La aportación valenciana (1963-2005), en la que es escasa la presencia femenina con artistas como Soledad Sevilla.

¿En qué punto estamos?

\section{Natalia Lozano}

Nace en Yecla en 1982, y desde la adolescencia ya muestra un incipiente interés por la fotografía a pesar de no tener los medios adecuados. Llega a la Facultad de Bellas 
Artes de Valencia, llevada por su interés por conocer los instrumentos artísticos y su fascinación por el arte.

Se trata de una artista que trabaja interesada en los medios audiovisuales, medio ideal para reflejar sus preocupaciones por el ser humano, siendo protagonistas la figura humana y el entorno que le rodea hoy en día, la infancia, la contaminación-reciclaje, la propia identidad que se corrompe en la sociedad actual y sobre todo la ciudad como lugar de paso, etc.

Excluyendo a la pintura, hay una búsqueda constante de nuevos lenguajes para expresar sus inquietudes, y este lenguaje lo encuentra sobre todo en la fotografía y el video arte, este último es uno de los medios más utilizado por la mujer en su lucha reivindicativa.

Intereses que se reflejan en sus obras como en la colaboración con Luismi Romero en Duerme (2006-08) veinte imágenes y una acción pública (imagen 1) que muestran el mundo de los sueños, la tranquilidad, que se puede dar en cualquier lugar, tanto en una cama como en una bañera. Para lograr estos objetivos se juega con la luz y el tiempo de exposición que ayudan a crear un ambiente de relajación absoluto, gracias al prolongado tiempo de exposición de la cámara fotográfica y al movimiento de una linterna que dibuja en el aire las líneas. Los rayos luminosos que se consiguen envuelven a las personas fotografiadas representando los sueños, se trata de dibujar con la luz líneas ondulantes que envuelven al personaje.

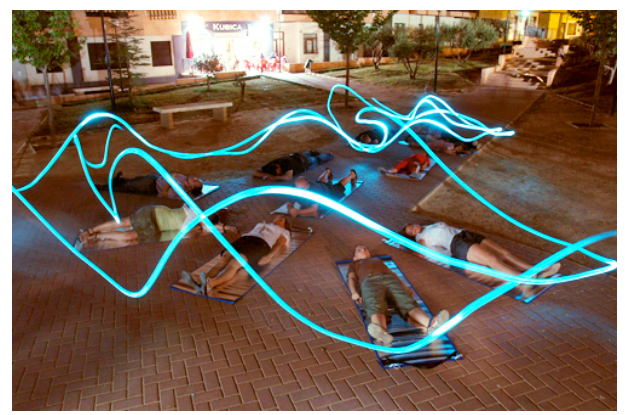

Figura 1. Acción pública Yecla duerme, Natalia Lozano, 2008

Cabe destacar los numerosos premios y selecciones que ha recibido esta serie de forma conjunta o individualmente como el Premio Autor Joven, XVI Certamen Fotografía Villa de Paterna (2007).

Otro trabajo que aúna esta preocupación por el instrumento utilizado y, a su vez, por el ser humano y aquello que le rodea es la serie Espejos espejismos. Fotografías realizadas en Santiago de Chile que muestran la ciudad y su vulnerabilidad, se centra en los problemas que surgen como la contaminación o la especulación y cómo repercuten en ésta o en su propia identidad.

Natalia utiliza la valla publicitaria como medio para mostrar estos problemas, la imagen dentro de la imagen, así el espectador tiene un mensaje directo para reflexionar. 
Por otro lado, cabe destacar una obra realizada, de nuevo junto a Luismi Romero, que se aparta de la fotografía. Realizan en 2007 una intervención llamada Reciclarte (imagen 2), en la que pretenden dar un nuevo uso a los objetos encontrados, en este caso en el rastro de la ciudad de Valencia. Realizan una intervención artística con la basura encontrada creando collages, composiciones, montajes, esculturas, es decir, arte reciclado pero a su vez efímero pues su duración llegaba a su fin con la llegada de los servicios de limpieza. Surge así un nuevo concepto llamado Basuarte.

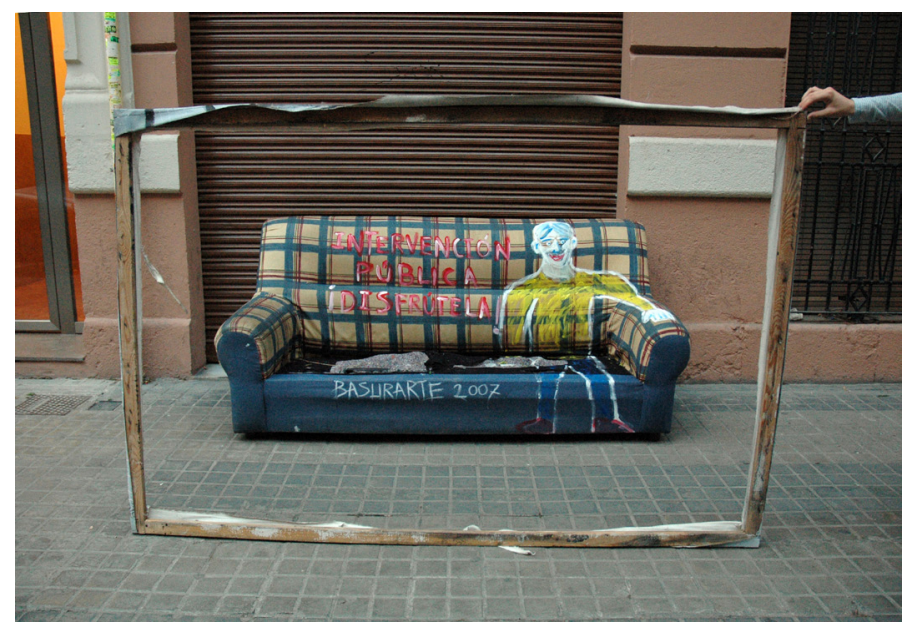

Figura 2. Reciclarte, Natalia Lozano y Luismi Romero, 2007

Este proyecto participa en Festival Internacional de Reciclaje Artístico DRAP ART 2007 de Barcelona.

Por último, en cuanto a fotografía se refiere, es importante la obra Alicia es un cuento, 2008. Serie de fotografías realizadas en Santiago de Chile, basadas en el cuento Alicia en el país de las maravillas de Lewis Carrol, pero que resulta más cercano al espectador pues adapta el discurso, los personajes, y los lugares a nuestra época, por ello Alicia aparece en lugares como una gasolinera, un restaurante, el metro. Natalia escribe la historia y al mismo tiempo la ilustra con las fotografías. Se intenta reflexionar sobre la existencia de dos realidades y se plantea una cuestión muy interesante que hoy en día todos nos hemos hecho alguna vez: ¿dónde acaba la realidad y empieza la ficción?

El hecho de que tome en sus fotografías siempre lugares de paso en la ciudad responde a la influencia del filósofo Marc Augé que reflexiona sobre los no lugares, es decir, lugares que tienen poca importancia en nuestras vidas por ser lugares de transitoriedad. La elección de este cuento se basa en su interés por la narración absurda y los hechos irreales y extraños que le van sucediendo a Alicia, donde se juntan ficción y realidad que nunca se puede diferenciar con certeza al igual que hacen y han hecho siempre los medios de comunicación. 
En cuanto Alicia, se trata de un personaje que se aleja al tópico de mujer occidental, sometido a la esclavitud de la imagen, de la belleza. Con ella Natalia pretende mostrar otro tipo de feminidad.

La obra se expone de dos maneras, aunque las dos traten lo mismo:

- Serie de veinte imágenes que incluyen título y texto

- Una serie de seis fotos sobre dibond, es decir, papel compuesto de dos láminas de aluminio.
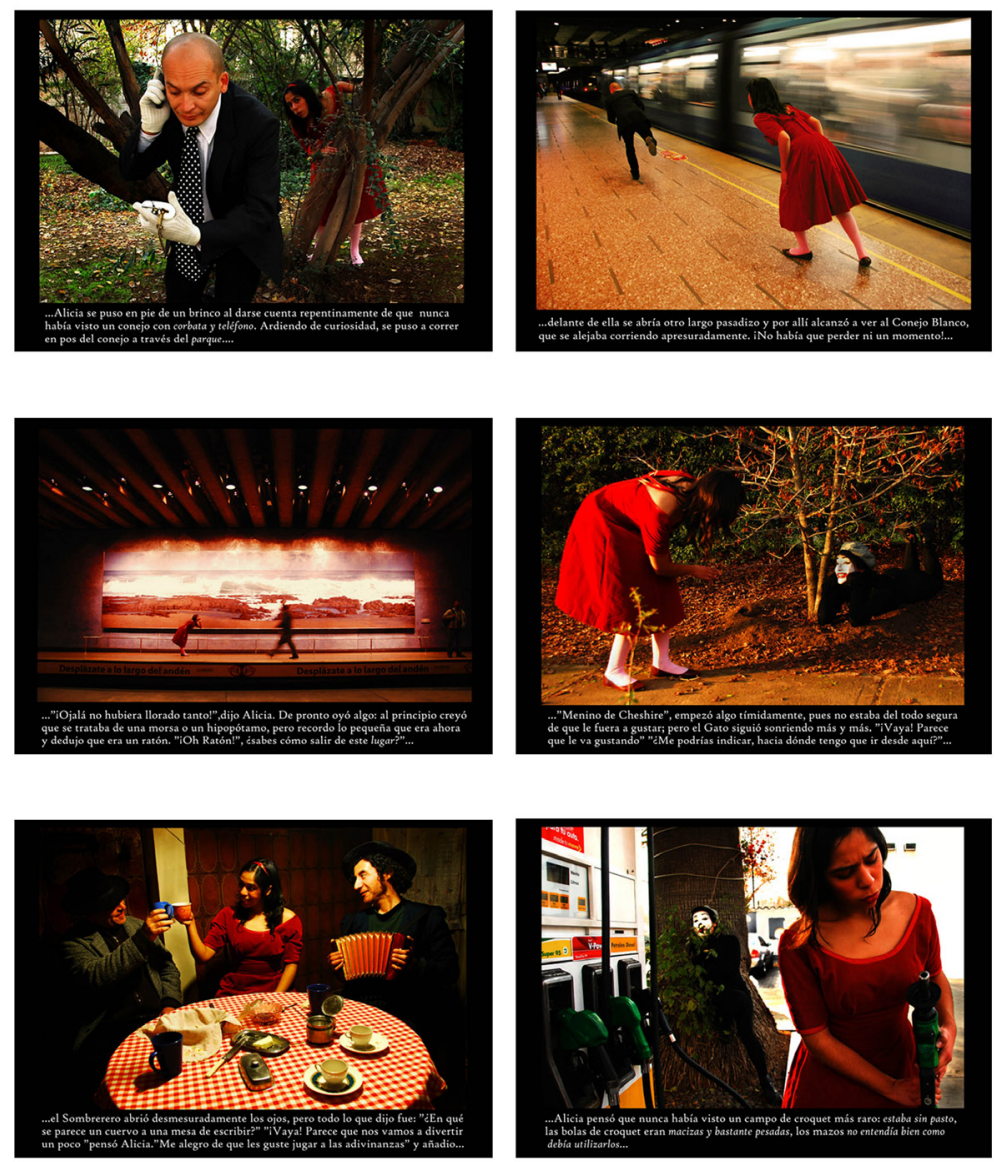

Figura 3. Alicia es un cuento, Natalia Lozano, 2008

Esta obra ha sido reconocida con diversos premios como el primer premio en la modalidad de fotografía en la $8^{\circ}$ Edición Valencia Crea 2008, además de participar en diversas exposiciones como en la Exposición colectiva en el Festival Valetudo Artístico 3, 2008.

Por otro lado, quiero resaltar también su producción de video-arte. Natalia pretende acercarse al espectador con un medio común a todos, con el que estamos muy 
familiarizados. Mediante técnicas como el collage pretende crear poemas visuales como lenguaje para transmitir sus mensajes.

En Lugares de ciudad (Figura 4) de nuevo se repite la idea de la ciudad como lugar de paso tal y como hemos visto en la obra de Alicia es un cuento. Poema audiovisual que muestra un lugar como un no lugar, es decir, lugar de tránsito, de prisas, de rapidez, de brevedad. Obra realizada junto a Luismi Romero que participa en la grabación. La obra se vuelve más enigmática gracias al sonido que juega un papel importante. Natalia toma el Conciertos para Violin y Cello de Henry Dutilleux, alternados con sonidos de transportes, sonidos de la calle o la televisión.

En el video, que tiene una estructura circular, vemos dos personajes que recorren la ciudad sin pararse a reflexionar sobre el lugar donde están, dos personajes que no parecen encontrarse en una ciudad en la que están encerrados y que les proporciona un gran sentimiento de soledad que se aprecia en el video mediante planos de calles desérticas. Los personajes intentan huir pero esa huida les lleva de nuevo a un espacio cerrado.

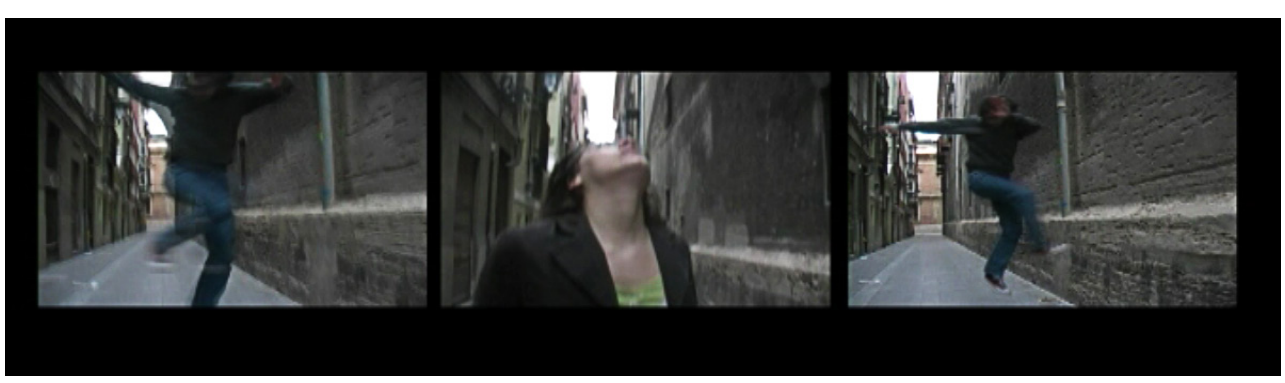

Figura 4. Lugares de ciudad, Natalia Lozano, 2008

A pesar de su corta carrera podemos apreciar una gran sensibilidad, y un conocimiento de la historia del arte que aprovecha en sus obras, además de un gran interés por el medio que utiliza intentando conocerlo en profundidad mediante experimentaciones antes de la creación de la obra definitiva. Su formación en bellas artes, la concesión de varias becas como la beca Promoe en la Universidad de Chile o la beca Leonardo en Budapest, además de un máster en Nuevas Tendencias y Procesos de Innovación en Comunicación componen un buen curriculum.

Una mujer, joven, que se enfrenta a diversas dificultades como la inexperiencia y que no se considera una mujer artista sino simplemente una artista.

\section{Lectura Postfeminista}

En torno a este tema, Rosa María Rodríguez Magda, catedrática en Filosofía, Consellera del Consell Valencià de Cultura y directora del Aula de Pensamiento de la Institució Alfons el Magnànim y de la revista Debats, contesta a una serie de preguntas que nos ayuda a entender un poco más la situación actual gracias a su gran experiencia sobre el tema avalada por sus numerosos trabajos acerca del feminismo. 
Con este trabajo se pretende conocer si la lucha reivindicativa de las mujeres, (centrándonos en el mundo artístico) hoy por hoy recoge sus frutos. Tomando a Natalia Lozano como referencia, una artista muy joven que ha participado en exposiciones y muchas de sus obras han sido premiadas y reconocidas, veo que ya se va reconociendo el trabajo de la mujer y que, poco a poco, está más integrada. Mi pregunta es ¿cree usted que se trata de una visión muy positiva?

Creo que la situación de la mujer en el mundo occidental ha mejorado sustancialmente, pero queda mucho por hacer, todavía la presencia de mujeres no es proporcional en los puestos clave de decisión. Se ha avanzado en la esfera política, pero no así en el mundo de los negocios, la economía... En el ámbito de la cultura el asunto es desigual, en la literatura, las artes plásticas, la interpretación teatral y musical, hay presencia femenina; pero en la ciencia, la filosofía, la sociología, la dirección de orquesta, la composición musical, la religión ... , por solo poner algunos ejemplos, su protagonismo es bastante escaso. Por otro lado, siguen muy vigentes los estereotipos de género con sus consecuencias en las relaciones personales, la escasa distribución del trabajo doméstico, la objetualización erótica de las mujeres...

Una cuestión que me preocupa al tener una actitud tan positiva es que, como apunta Amelia Valcárcel en Feminismo en el mundo global, es que se crea que por mi juventud ya pienso que está todo solucionado y todo conseguido y nada más lejos de la realidad, aún queda mucho por hacer pero, ¿se podría decir que estamos en un parón reivindicativo tras el postfeminismo?

Sí, la aparente igualdad hace menos perceptibles las discriminaciones. Las jóvenes creen haberlas superado, pero se dan de bruces con ellas cuando, por ejemplo, entran en la vida laboral, constituyen una pareja, desean ser madres. Y entonces carecen de armas teóricas para analizar esas situaciones, pues el feminismo tiene mala prensa y sus textos se consideran algo caduco. No se ha mantenido una reflexión crítica, que hace unas décadas surgía casi espontáneamente, pues las cortapisas eran más evidentes. Existen unos usos aparentemente liberadores en las relaciones entre los sexos, pero que en el fondo transmiten roles muy reaccionarios. Pienso que ha descendido el umbral de percepción de lo que es indigno o potencialmente violento.

Si como dice usted en su obra Femenino Fin de Siglo, el hombre-amo ha logrado serlo porque ha conseguido que su deseo de las cosas se cumpla por medio del dominio y anulación de otro deseo: el de la mujer, esto se puede entender, aplicándolo a la historia del arte, que el hombre ha anulado a la mujer como artista a lo largo de la historia para poder imponer su deseo, es decir, el hombre ha apartado el deseo de la mujer para que sobresalga el suyo. Hoy en día, ¿se podría decir que el hombre está cediendo al deseo de la mujer, pues vemos que su trabajo está siendo más reconocido, o es la mujer la que se impone y da un paso adelante? 
En el arte, como en otros ámbitos, el protagonismo lo han tenido los varones, debido sobre todo a la dificultad de que las mujeres pudieran desarrollarse pública y profesionalmente en este aspecto. Cuando con grandes esfuerzos han logrado destacar, la crítica las ha considerado menores y han quedado oscurecidas por sus compañeros, recordemos por ejemplo a Berthe Morisot, Camille Claudel o Maruja Mallo... Su ausencia ha hecho que el imaginario artístico haya sido casi totalmente masculino. Por eso es tan importante que las creadoras desarrollen su mirada. En este sentido me parece muy importante el revulsivo de cierto arte feminista: Nancy Spero, Ana Mendieta, Cindy Sherman... Pero también me lo parece el hecho de que la presencia de mujeres artistas sea algo normalizado y no se constituya un guetto, que en última instancia minorizaría "el arte de mujeres" frente al Arte con mayúscula.

Por último, en su texto Feminización de la cultura, hace una conclusión con la que estoy muy de acuerdo, resulta concluyente la necesidad de que las mujeres produzcan cultura...de forma que en la cultura no seamos siempre huéspedes ocasionales... Y en eso estamos. Natalia Lozano es un claro ejemplo de cómo la actividad femenina se inserta en la cultura, por lo tanto, ¿hemos llegado a un punto en el que la mujer puede insertarse sin necesidad de hacer de su actividad algo reivindicativo y feminista?

Lo importante no es no querer ser feminista, si no que no fuera necesario serlo. Ahora bien, no considero que el arte deba estar al servicio de una causa, pues lo que gana como agitación lo pierde muchas veces en hondura. No creo que haga falta estar constantemente preguntándose ¿qué es lo que tengo que hacer puesto que soy mujer? Hay que producir una obra relevante, y seguramente cuantas más mujeres haya más rica será la aportación global al arte.

Tras estas reflexiones vemos como desde hace ya unos años aquello que era exclusivamente masculino como puede ser la política, la cultura, las empresas, etc. ha dejado paso también a la mujer y esto es lo que puede llegar a confundir a éstas mismas pues parece que ha llegado un momento de igualdad, de oportunidades por igual entre hombres y mujeres, y sí, es cierto que se ha logrado mucho, pero se debe llegar a un punto en el que la mujer no deba justificarse y que su aportación sea la misma que la aportación masculina en todos los sectores.

Hoy en día aún quedan muchas trabas que debe superar la mujer y muchos estereotipos que aún nos marginan, pero tras tantas luchas al hombre no le queda otra que reconocer que la mujer tiene también su lugar en la sociedad y que poco a poco se está ocupando.

La mujer ya no tiene miedo, no tiene vergüenza y sabe a qué se enfrenta por lo cual se hace más fuerte. Natalia Lozano es una de ellas, se presenta en un ambiente que hasta hace unas décadas era masculino, y trabaja sin pensar que es una mujer, sin necesidad de reivindicación, muestra su talento y hace lo que le gusta y haciendo más fructífero y más valioso el arte en este caso. 


\section{Conclusiones}

En la actualidad la mujer va adquiriendo mayor protagonismo y eso es algo que nadie puede discutir. La mujer tiene acceso al trabajo, a estudiar, ha llegado a la política en numerosos países, es libre y disfruta de sus derechos exceptuando algunos países cuya religión la margina. Pero todos estos logros pueden llevar a pensar que el camino ya está hecho, por lo que se puede dar un parón reivindicativo pues la sensibilidad de la mujer actual ha disminuido como pasó durante la década de los cincuenta cuando las mujeres, en general, conservaban aún ideas atrasadas y tradicionales como quedarse en casa para dedicarse de su marido e hijos sin voz ni voto.

Con este estudio no pretendo dar a entender que la mujer tiene las puertas abiertas y que está todo hecho. Amelia Valcárcel habla del espejismo de igualdad ${ }^{6}$, es decir, de la influencia que ha dejado el feminismo sobre las mujeres actuales, que dan por hecho que ya está todo conseguido aunque no se sepa ni por qué ni gracias a quién. Obviamente esto no es lo que viene a decir este trabajo. Con los datos tan positivos que se han dado al hablar de la última Bienal de Venecia se pretende mostrar la evolución y la integración de la mujer gracias a toda la lucha feminista y, más tarde, postfeminista, en la que vemos que no sólo se destaca el trabajo de una artista consagrada como Yoko Ono, sino que también se abre paso a nuevas generaciones como Nathalie Djurberg. Vemos como, poco a poco, no es necesario ser una mujer con una gran trayectoria tras la espalda para que reconozcan tu trabajo si no que la mujer joven se está abriendo paso.

Natalia Lozano es un ejemplo de jóvenes mujeres que intentan romper las barreras del machismo mediante su trabajo. A pesar de que éste no sea explícitamente feminista el hecho de que se luche por sus derechos y que intente abrirse un hueco en el mundo del arte es una pelea continua.

Siempre he pensado que el arte se puede encontrar en todos los campos de la vida, Se integra con la ciencia, la filosofía, la mitología, el lenguaje, la danza, la música, la poesía ...el arte alberga cualquier sistema que parte del conocimiento y de la conciencia humana. El arte nos engloba. El arte es la conexión entre los aparatos funcionales y las sensaciones y percepciones que tiene el sujeto, es la integración de lo desconocido en lo conocido.

Con estas palabras de Natalia Lozano entendemos que el arte nos rodea, que el arte pertenece a todos y que se encuentra en todo. Mujeres y hombres son partícipes de él y todos somos capaces de crearlo y de entenderlo.

La conciencia feminista acompaña en la actualidad a las jóvenes por ello creemos en la igualdad, en los derechos de la mujer, en la libertad de expresión. Es algo que está aceptado por toda mujer y que inconscientemente se busca en nuestra sociedad.

La mujer debe integrarse en la cultura y dejar de ser huéspedes ocasionales tal y como afirma Rosa María Rodríguez ${ }^{7}$. Así, la vida en todos sus ámbitos será mucho más rica y apreciada por todos pues la aportación femenina estará presente. 


\section{Referencias}

Cacace, M. (2006). Mujeres jóvenes y feminismo. Valores, cultura y comportamientos frente a frente. Madrid: Narcea.

López de la Vieja, M ${ }^{a}$ T. (2000). Feminismo del pasado al presente. Salamanca: Universidad Salamanca.

Mania, P. (2007). Teoria e prassi il feminismo nel sistema dell'arte dagli anni 70 ad oggi. Luxflux. Recuperado de http://www.luxflux.net

Navarrete, C., Ruido, M., Vila, F. (2005). Trastornos para devenir: entre artes y políticas feministas y queer en el estado español. Desacuerdos 2: Barcelona, Museu d'Art Contemporani de Barcelona, MACBA; San Sebastián, Arteleku; Sevilla, Universidad Internacional de Andalucía. pp. 158-187.

Rodríguez Magda, R. M. (1994). Femenino Fin de siglo. La seducción de la diferencia. Valencia: Anthropos.

Rodríguez Magda, R. M. (2002). Feminización de la cultura. Debats, (76).

Varárcel, A. (2008). Feminismo en el mundo global. Madrid: Ediciones Cátedra.

Wilding. F., \& Critial Art Emsemble. (2009). Notas sobre la condición política del Cyberfeminismo. Recuperado de http://www.estudiosonline.net/texts/cae politic.html

\section{Notas}

1. Carmen Navarrete, María Ruido y Fela Villa. Trastornos para el devenir: entre artes políticas y feministas queer en el Estado Español, Pág. 165.

2. Patrizia Maino, Teoria e prassi al feminile nel sistema dell'arte dagli anni 70 ad oggi. Articoli tematici, Luxflux, Pág.1.

3. Faith Wilding \& Critial Art Emsemble, Notas sobre la condición política del Cyberfeminismo.

4. Marina Cacace; Mujeres jóvenes y feminismo. Valores, cultura y comportamientos frente a frente, Pág. 32 .

5. Mª Teresa López de la Vieja, Feminismo del pasado al presente, Pág.142.

6. Amelia Valcárcel; Feminismo en el mundo global, Pág. 201.

7. Rosa maría Rodriguez Magda. Texto Feminización de la cultura. 